\title{
A Markov chain model of the evolution of complex neuronal network structures in the presence of plasticity
}

\author{
Nana Arizumi, , Todd P Coleman, R Lee DeVille \\ From Nineteenth Annual Computational Neuroscience Meeting: CNS*2010 \\ San Antonio, TX, USA. 24-30 July 2010
}

We consider neuronal network models with plasticity and randomness; we show that complicated global structures can evolve even in the presence of simple local update rules. Our models are discrete in time and our analysis uses tools from the theory of Markov chains.

Specifically, we propose a discrete-time model of the evolution of a neuronal network capable of learning with multiple input neurons (whose spiking consists of Poisson processes), one output integrate-and-fire neuron, and a network with conductances between them. Along with the input firing, the stochasticity of the output neuron's state is modulated by the conductances in the network, that evolve according to synaptic plasticity in the form of long-term potentiation. The aggregate system evolves according to discrete-state, multi-dimensional Markov chain. We demonstrate that the network is capable of rich properties (e.g. bifurcation, various forms of stability, etc) that depend on maximum possible values of conductance, the rates of the Poisson processes, and the number of levels in the integrate-and-fire output neuron model. Most importantly, we believe that this approach provides a well-positioned balance between neuro-biological relevance and ability to be analyzed theoretically. In the future, we plan to apply principles from Lyapunov exponents (for sensitivity to initial conditions) and information theory (using the KL divergence for model order reduction and employing feedback information theoretic principles using the directed information to elucidate information dynamics) so that the key emerging principles underlying the complex behaviors can be illustrated in a provably good manner.

* Correspondence: arizumi@illinois.edu

University of Illinois at Urbana Champaign, USA
Published: 20 July 2010

doi:10.1186/1471-2202-11-S1-P61

Cite this article as: Arizumi et al.: A Markov chain model of the evolution of complex neuronal network structures in the presence of plasticity. BMC Neuroscience 2010 11(Suppl 1):P61.
Submit your next manuscript to BioMed Central and take full advantage of:

- Convenient online submission

- Thorough peer review

- No space constraints or color figure charges

- Immediate publication on acceptance

- Inclusion in PubMed, CAS, Scopus and Google Scholar

- Research which is freely available for redistribution

Submit your manuscript at www.biomedcentral.com/submit
C Biomed Central 